\title{
Review
}

\section{Management of pharynx fistula after upper digestive tract instrumentation}

\author{
Bogdan Popescu ${ }^{1,2}$, Ștefan Voiculescu', Răzvan V. Scăunașu ${ }^{1}$, Alexandra O. Păun², \\ Şerban V.G. Berteșteanu ${ }^{1,2}$, Cristian R. Popescu ${ }^{1}$ \\ ${ }^{1}$ Carol Davila University, Faculty of General Medicine, Bucharest, Romania \\ ${ }^{2}$ Colțea Clinical Hospital, Department of E.N.T. and H.N.S., Bucharest, Romania
}

\begin{abstract}
Pharynx fistula is a pathological state that can pose serious problems for both physician and patient and can lead up to the death of the patient in complicated cases.

The authors describe a series of guidelines for the management of the pharynx fistula regarding the complications of the instrumentation of the upper digestive tract.

Most of the cases that are addressed to our clinic can be treated with a conservative approach and a nutrition therapy plan tailored to each case. In selected cases surgery is the method of choice for therapy.

The management of the pharynx fistula can be well managed in a multidisciplinary approach using resources from the E.N.T. and H.N.S. department and more important from the ICU department.
\end{abstract}

Keywords: nutrition, pharynx, iatrogenic, fistula 


\section{Introduction}

Pharynx fistula is a pathological state that account for most of the complications following total laryngectomee, is encountered in patients with extensive neck trauma with a blunt or a sharp object, might appear after the instrumentation of the upper digestive tract when attempting diagnostic or therapy procedures or might be present from birth as part of a partial or complete syndrome of malformations. The management of the pharynx fistula involves the need of a solid history of the patient's disease, means o occurrence, prior therapy, which includes surgery, radiotherapy, and the evaluation of the current condition (Figure 1). The therapy plan needs to be tailored for each case so that the recovery is to be maximum and the morbidity needs to be decreased, ideally to minimum.

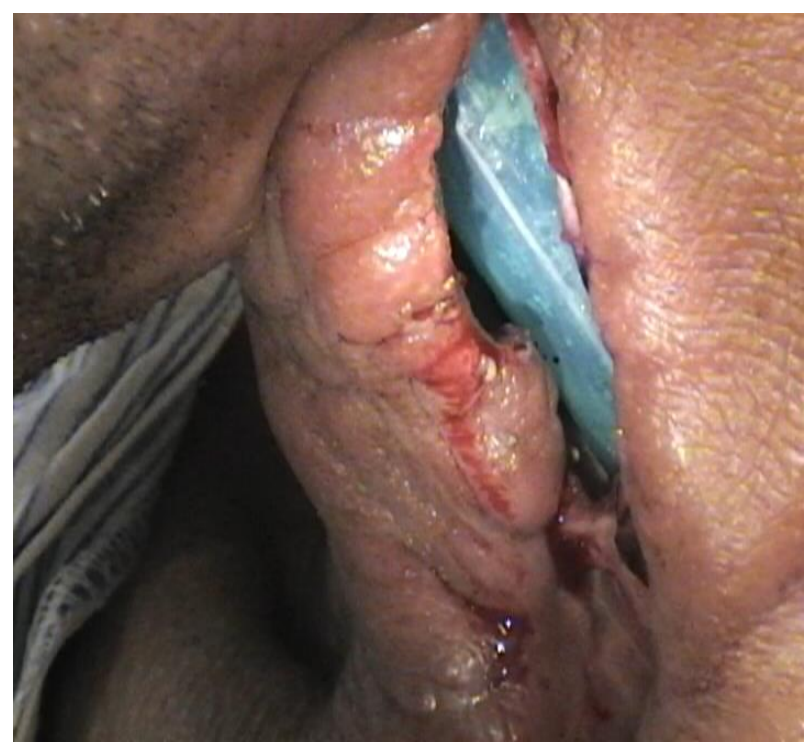

Figure 1. Pharynx fistula in a patient with total laryngectomy and adjuvant radiotherapy for the neck region

One of the key aspects of pharynx fistula presence is the situation in which this particular pathology develops after a diagnostic procedure performed by a physician. This case is subject to interpretation due to the legal implications deriving from a malpraxis. Instrumentation of the upper digestive tract is done to scope the digestive tube when performing an upper digestive tract endoscopy, when performing a trans-esophageal echocardiogram or when performing a bronchoscopy. The instruments used for this diagnostic or therapy maneuvers are blunt and are designed particularly not to injure the digestive mucosa or the surrounding tissues. However, when the patient associates abnormalities in the pharynx region the instrumentation can be followed by the appearance of a fistula.

The abnormalities that may pose problems for the physician include exostosis or trauma of the cervical vertebrae with the narrowing of the pharynx lumen and the bulging of tissue covered with digestive mucosa (Figure 2). The passage of the instruments through the pharynx needs to be gentle, slowly progressive and without jerking the instrument. If the procedure is performed, without prior investigation by an E.N.T. specialist, there might be complications arising from the incomplete knowledge of the anatomy and topography of the pharynx passage. This is why a panendoscopic examination with flexible scopes should be performed.

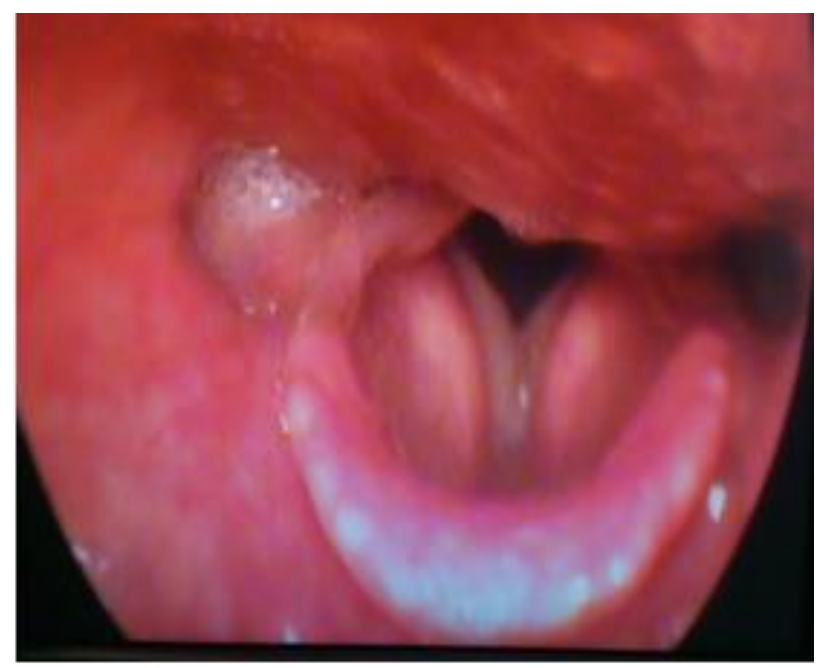

Figure 2. Endoscopic view of the hipopharynx and the larynx

Bulging of an osteophyte of the $4^{\text {th }}$ vertebrae in the lumen of the hypopharynx, associating oedema, erithema and the presence of a $1,5 \mathrm{~mm}$ fistula caused by instrumentation for trans-esophageal echocardiograhpy. 
Feeding tube guidelines. In the case of a This can be performed either by chest X-ray or direct pharynx fistula, whatever the cause of appearance, the physician must ensure that the patient will receive food and beverages through the digestive tract. Enteral nutrition is preferred to parenteral one if the gut if functional. The indications for feeding tube placement are shown in Table 1.

\begin{tabular}{|c|c|}
\hline \multicolumn{2}{|c|}{ Table 1. Indication for feeding tube placement } \\
\hline $\begin{array}{c}\text { General indications } \\
\text { stomach }\end{array}$ & Pharynx fistula \\
\hline Decompression of the & Enteral nutrition \\
\hline Gastric wash & Placing the fistula at \\
\hline Motility digestive \\
disease diagnosis
\end{tabular}

The physician should not place a feeding tube if the patient has diffuse peritonitis, severe pancreatitis, intestinal obstruction or ileus. However, there are relative contraindications for feeding tube placement that need to be assessed by the physician and the therapy decision must be taken according to the particularity of the case. The relative contraindications include tumors of the nasal fossa, trauma of the nose and face, nose bleeding, nasal surgery, anticoagulant therapy, altered mental status and an exacerbated vomit reflex.

Placing of the feeding tube is usually performed by the ICU personnel as a routine maneuver. Still, in pharynx fistula cases the verification of the feeding tube placing is mandatory for the E.N.T. specialist. view with the aid of pharynx endoscopy. Some complications may occur when placing a feeding tube (Table 2). The E.N.T. specialist and the ICU practitioner need to be aware of them since some of the complications are life-threatening.

\begin{tabular}{|c|c|}
\hline \multicolumn{2}{|c|}{ Table 2. Feeding tube complications } \\
\hline Feeding & Placement \\
\hline $\begin{array}{c}\text { Cloting } \\
\text { (most frequent) }\end{array}$ & Nose bleeding \\
\hline $\begin{array}{l}\text { Dumping } \\
\text { syndrome }\end{array}$ & $\begin{array}{c}\text { False pathway - Zenker } \\
\text { diverticulum }\end{array}$ \\
\hline \multirow[t]{4}{*}{ Aspiration } & $\begin{array}{l}\text { Aspiration with } \\
\text { bronchopneumonia }\end{array}$ \\
\hline & $\begin{array}{l}\text { Upper digestive } \\
\text { hemorrhage }\end{array}$ \\
\hline & Contact ulcer \\
\hline & Bradicardia/asystole \\
\hline
\end{tabular}

\section{Discussion}

The main problem with patients with the impossibility of oral food intake is that if the small intestine is not used the villi will atrophy and the absorption of nutrients, ions and water will be impaired leading to short term complications in the homeostasis. Because of this early enteral nutrition is required (1). Along with this there are several issues that need to be taken into consideration regarding the use of a nasogastric tube. Some patients with pharynx fistula might be uncooperative and there are reported cases of patients extracting their nasogastric tubes and self-administering food and beverages orally despite medical advice. The close relations of the parapharynx spaces with the upper mediastinum means that the leak of septic content through the pharynx fistula might gravitationally end up in the thorax. This severe situation can cause sepsis, mediastinitis and has a high 
rate of mortality (2). The risk of complications decreases with the shorter time form the diagnostic to the specific therapy (3). The biological status is an aggravating factor with even greater complications when patients associate diabetes mellitus, malnutrition, immunodeficiency, prior chemotherapy or radiotherapy, transplant.

In large pharynx fistula therapy management includes surgery as the first step with or without flap manufacturing or the use of synthetic materials. Surgery might rises other issues in wound healing such as associated infection, insufficient pharynx tissue, intolerance to the surgical materials, inadequate surgical technique, mistreatment in the postoperative period, digestive problems such as acid reflux or vomiting. All of this taken into consideration lead the surgeon to the development of a therapy plan which needs to include nutritional management and ICU care.

Regarding the nutrition management physicians overlooking patients with acute status caused by the presence of the pharynx fistula need to amend biological needs of an increased metabolism. The nutrition guidelines (4) state that for high catabolism patients, which is the case of acute status in pharynx fistula patients, the panel of intake should be:

- $30-35 \mathrm{kcal} / \mathrm{kg} / \mathrm{day}$ (from the absolute body mass)

- $1-2 \mathrm{~g}$ proteins $/ \mathrm{kg} /$ day (20\% intake)

- lipids - moderate intake (30\%-50\%) with PUFA $\omega$ - 3 supplements

- low intake of carbohydrates

- antioxidants.

\section{Conclusions}

The management of patients with pharynx fistula after upper tract instrumentation implies o correct diagnosis and tailored therapy for selected cases. In cases in which the pharynx fistula is larger than $1 \mathrm{~cm}$ should be treated with surgery as a primary therapy. Smaller lesions benefit from conservative therapy. Anti vomiting drugs should be administered along with the medication for acid reflux. The physician should take note that the presence of the nasogastric tube placed for enteral feeding prolongs the interval of recovery due to the close contact with the tearing region of the pharynx mucosa. This is why the nasogastric tube must be placed under endoscopic control, so that it would not be in direct contact with the fistula.

If the nasogastric tube cannot be placed or if the patient's status does not allow it the nutrition should be parenteral. Pharynx fistulas to the skin prolong the hospitalisation period, with increased costs and possibly multiple surgical interventions. Pharynx fistulas can cause the death of the patient by severe sepsis and MOSF if mistreated or if the therapy is delayed.

Pharynx fistulas can be a consequence of paraclinical investigation of the upper digestive tract, trans-esophageal echocardiography or bronchoscopy. This is why it is mandatory to have an E.N.T. panendoscopic examination of the pharynx and, if needed, a plane X-ray of the cervical vertebrae should be performed.

\section{References}

1. Reintam Blaser A, Starkopf J, Alhazzani W, Berger MM, Casaer MP, Deane AM, Fruhwald S, Hiesmayr M, Ichai C, Jakob SM, Loudet CI, Malbrain ML, Montejo González JC, PaugamBurtz C, Poeze M, Preiser JC, Singer P, van Zanten AR, De Waele J, Wendon J, Wernerman J, Whitehouse T, Wilmer A, Oudemans-van Straaten HM; ESICM Working Group on Gastrointestinal Function. Early Enteral Nutrition In Critically Ill Patients: Esicm Clinical Practice Guidelines. Intensive Care Med. 2017; 43(3): 380-398. PMID: $28168570 \quad$ https://doi.org/10.1007/s00134-016$\underline{4665-0}$

2. Zhang X, Liu Z, Li Q, Liu X, Li H, Liu W, Li Q, Guo Z, Zeng Z. Using a linear stapler for pharyngeal closure in total laryngectomy. Eur Arch Otorhinolaryngol. 2013; 270(4): 1467-71. 
PMID: 22986414 https://doi.org/10.1007/s00405012-2180-7

3. Punthakee $X$, Zaghi S, Nabili V, Knott PD, Blackwell KE. Effects of salivary bypass tubes on fistula and stricture formation. JAMA Facial Plast Surg. 2013; 15(3): 219-25. PMID: 23519300 https://doi.org/10.1001/jamafacial.2013.791

4. Antanavicius G, Leslie D, Torres-Villalobos G, Kellogg T, Ikramuddin S. Percutaneous endoscopic gastrostomy tube insertion via gastrogastric fistula in a gastric bypass patient. Obes Surg. 2010; 20(7): 957-9. PMID: 18820979 https://doi.org/10.1007/s11695-008-9695-4

5. Parelkar S, Mundada D, Joshi P, Sanghvi B, Kapadnis S, Oak S. Iatrogenic perforation of upper pouch in pure esophageal atresia: a rare complication and review of literature. European $J$ Pediatr Surg Rep. 2013; 1(1): 21-3. PMID: 25755943 https://doi.org/10.1055/s-0033-1341417

6. Knight RB, Webb DE, P Coppola C. Pharyngeal perforation masquerading as esophageal atresia. $J$ Pediatr Surg. 2009; 44(11): 2216-8. PMID:
19944236

https://doi.org/10.1016/j.jpedsurg.2009.10.050

7. Süslü N, Senirli RT, Günaydın RÖ, Özer S, Karakaya J, Hoşal AŞ. Pharyngocutaneous fistula after salvage laryngectomy. Acta Otolaryngol. 2015; 135(6): 615-21. PMID: 25762119 https://doi.org/10.3109/00016489.2015.1009639

8. Zhang $\mathrm{P}$, Tian X. Recurrent neck lesions secondary to pyriform sinus fistula. Eur Arch Otorhinolaryngol. 2016; 273(3): 735-9. PMID: 25708412 https://doi.org/10.1007/s00405-015$\underline{3572-2}$

9. Dedivitis RA, Aires FT, Pfuetzenreiter EG Jr, Castro MA, Guimarães AV. Stapler suture of the pharynx after total laryngectomy. Acta Otorhinolaryngol Ital. 2014; 34(2): 94-8. PMID: 24843218

10. Bergeron JL, Chhetri DK. Indications and outcomes of endoscopic $\mathrm{CO} 2$ laser cricopharyngeal myotomy. Laryngoscope. 2014; 124(4): 950-4. PMID: 24114581 https://doi.org/10.1002/lary.24415 